\title{
Die Letzten werden die Ersten sein
}

\section{Christina Aus der Au}

Prof. Dr. theol., Mitglied der Redaktion Ethik

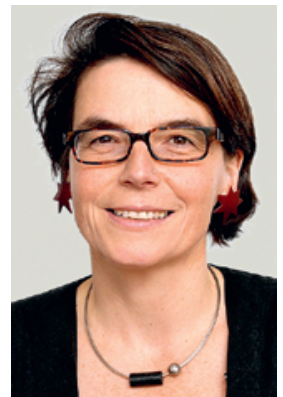

Es gibt eine neue Saison: die Impfsaison! Sie hat im Januar angefangen und dauert nun die nächsten Monate an. Die einen schimpfen über sie, die anderen konnten es nicht erwarten, bis sie endlich anfängt - wie immer bei den Saisons halt.

Die Impfsaison hat allerdings besonders heftige Reaktionen hervorgerufen - wohlgemerkt, nicht die Impfung, sondern die Saison. Nur schon bis alles bereit war - die Impfstoffe, die Zentren, die Anmeldungsinfrastruktur. Und nicht zuletzt die Menschen! Da harzt und knarzt es fast noch am meisten; die einen streiken, die anderen drängeln. Wenn man doch wenigstens sagen könnte: «Wär nöd wott, hät ghaa!» Das Problem ist nämlich: Geimpft wird man nie nur ganz alleine, sondern immer auch als Mitglied einer Gemeinschaft. Ich lasse mich impfen, damit ich selber nicht krank werde - aber auch, damit ich die Krankheit nicht weitergeben kann. Oder ich lasse mich nicht impfen, weil ich glaube, mich dadurch einer höheren Macht auszuliefern, die damit der Weltherrschaft einen Schritt näherkommt. Oder vielleicht auch, weil ich der dahinterstehenden Pharmaindustrie nicht traue. Jedenfalls betrifft meine Entscheidung nie nur mich selber, sondern es ist geradezu ein politisches Statement, Me too sozusagen ...

Wenn wir uns einmal auf die Seite der Impfbefürworter und -befürworterinnen stellen wollen (was ich gerne tue), dann ist allerdings die Frage, wer denn zuerst geimpft werden soll, nicht weniger politisch! Wer wird sozusagen dem Ansteckungsrisiko zuerst entrissen, und wer ist noch etwas länger - im schlimmsten Fall viel länger - diesem fiesen Virus ungeschützt ausgesetzt?

Man könnte nun denken angesichts dessen, was unsere Gesellschaft und vor allem unsere Wirtschaft in den letzten Monaten ertragen mussten, es gäbe gute Gründe dafür, zuerst den werktätigen Teil der Bevölkerung zu impfen. So wie offenbar in Indonesien, wo die 18- bis 59-Jährigen prioritär geschützt werden sollen. Sie seien diejenigen, die viel unterwegs seien, und dadurch könne die Produktivität des Landes sichergestellt werden. Auch Boris Palmer, der Bürgermeister aus dem württembergischen Tübingen, kritisierte die Massnahmen der ersten Corona-Welle: «Wir retten in halben Jahr sowieso tot wären - aufgrund ihres Alters und ihrer Vorerkrankungen.»

Er allerdings erntete einen grossen Shitstorm. Deutschland und die Schweiz, zusammen mit vielen anderen Ländern, haben sich entschieden, nicht zuerst die Starken, die Produktiven, die Einflussreichen zu impfen. Sondern die Menschen auf der anderen Seite, die alten und schwachen Menschen, diejenigen mit Vorerkrankungen, die Frauen und Männer in Altersund Pflegeheimen. Diesen Menschen soll zuerst Sorge getragen werden, ihnen und denjenigen, die sie pflegen und betreuen. Sie kommen zuerst, wenn es um die Verteilung des noch knappen Impfstoffes geht. Nicht weil es die Wirtschaft am nötigsten hat, sondern weil sie es am nötigsten haben.

«(D)ass die Stärke des Volkes sich misst am Wohl der Schwachen", steht in der Präambel der Schweizerischen Bundesverfassung. Vielleicht ist es gar nicht so sehr der Neid, der die Wogen hochschlagen lässt, wenn sich die Millionäre und die Mehrheitsaktionäre vordrängeln. Sondern schlicht die tiefe und intuitive Überzeugung, dass es gerade hier nicht darum gehen darf, wer die spitzeren Ellbogen hat und das dickere Portemonnaie. Sondern darum, welche Werte eine Gesellschaft tragen.

Die Letzten werden die Ersten und die Ersten die Letzten sein. Das sagt Jesus im Matthäusevangelium zu denjenigen, die sich ungerecht behandelt fühlen. Die am Schluss der Schlange standen, erhalten gleich viel wie die an der Spitze. Nicht hier auf Erden; hier sind und bleiben sonst meistens die Ersten die Ersten. Hier gilt eher der Satz - auch aus dem Matthäusevangelium - «wer hat, dem wird gegeben» (das nennt man auch den «Matthäus-Effekt»).

Die erste Geschichte hingegen ist ein Ausblick ins Reich Gottes, dort, wo andere Regeln herrschen als das Überlebensrecht des Stärkeren. Spannend, dass wir uns ausgerechnet in einer solchen Krise, wie sie diese Pandemie darstellt, daran erinnern, wie es anders sein könnte. Wie eine Gesellschaft sein kann, wenn sie sich um das Wohl der Schwächsten sorgt und ihnen besonderen Schutz zukommen lässt. Die Letzten sind so zu Ersten geworden.

Jedenfalls beim Impfen. Ob das wohl noch durchblitzt, wenn die Zeiten wieder anders werden? 